\title{
RIPPLE EFFECT ON HOUSING PRICES. EVIDENCE FROM TOURIST MARKETS IN ALICANTE, SPAIN
}

\author{
Paloma TALTAVULL de LA PAZ a,*, Enrique LÓPEZ a, Francisco JUÁREZ a \\ a Department of Applied Economics, University of Alicante, Campus de San Vicente del Raspeig $s / n$, \\ 03080 Alicante, Spain
}

Received 17 June 2015; accepted 28 October 2015

\begin{abstract}
This paper analyses the house price diffusion effect in an economic-mixed region where the costal amenities strongly attracts second home and temporal residents while the main region's city is an administrative centre in Alicante province, Spain. The region is called Vega Baja country with 2 well known foreign-Europeans destination areas are located (Orihuela costa and Torrevieja). Using geo-referenced data, the paper explores the ripple effect on house prices between the coastal and inland areas, versus Orihuela capital. To control by heterogeneity and spatial autocorrelation, the model estimates housing prices controlled by quality including 33 house characteristics and spatial autocorrelation applying an SAR-hedonic based model which is estimated yearly for the period 2007-2012. Once controlled by quality, the estimated prices are used to seek 3 evidences of ripple effect: with spatial contiguity (spatial diffusion in the short distance), without special contiguity (long distance) and constant relative prices ratio, using Lagrange Multiplier test and Moran's I, and Spatially Weighted Two Stage Least Squares (SW2SLS) including spatial lag and errors in the model. Results show the existence of spatial autocorrelation patterns in a well-defined local clusters and highlight evidence of ripple effect between Orihuela city and the coastal and inland areas but with lagged effect.
\end{abstract}

KEYWORDS: Housing prices; Ripple effect; Tourist areas; Spain

SUPPLEMENTARY MATERIAL associated with this article can be found, in the online version, at https://doi.org/10.3846/1648715X.2016.1241192

\section{INTRODUCTION}

House prices have received increasing attention since the start of the Global Financial Crisis (GFC) because many has seen in the house price sinking to have part of the crisis responsibility. The EU authorities included house price growth rate into the list of indicators to be followed to monitoring (macro) economic imbalances and it is also recognized that house prices have played a role in the lack of household affordability to housing therefore, having social impacts. This interest grew after a long list of analysis deepening on how the housing bubble formation happened, and giving different evidence about how the three different groups of variables (the general-global influences, the specific-local demand shocks and the diffusion effects from other closer areas) affected to prices.

\footnotetext{
* Corresponding author. E-mail: paloma@ua.es
}

It is documented how housing (aggregate) prices depend on the fundamental drivers associated to the economic and social dynamism (for instance migration, economic growth or the financial system efficiency) although a relevant part of those influences happen at local level as a response to a demand shock. Local house prices also diffuse and interact to other prices in the closer markets transmitting their influences among the territory in the long run. It is recognized that housing prices maintain a weighted relationship in the long run with other regions' ones showing a long term equilibrium in the relative house price among regions in the long run (Meen 1999; Holmes, Grimes 2008 among others).

The literature agrees that house prices depend on the local demand characteristics and that differ across markets. A controversy opinion appears 
when the same "local" area includes housing markets with differenced features for example, when both local and tourist demand concurs in the same territory. The economic logic suggests that the confluence of different socio-economic demand features (like income, tastes, demography, willingness to pay) that affects differently to housing prices in a very local area with no further reason (demand exchange) to think that they could affect to the general prices for proximity. What the international evidence demonstrates is that, by diffusion to the territory, a shock in house price in one market could be transmitted in the short (spatial effect) or in the long run (ripple effect).

During last decade, housing prices have suffered the impact of the GFC with strong reduction on their levels in most develop countries. In Spain, that crisis was followed by a subsequent crisis produced by the fall in consumption and investment due to the austerity policy measures applied by the government. Most economic indicators show those effects in macro aggregates as a double " $v$ " in two well defined periods, 2007-2009 and 2010-2014, whilst some research have demonstrated the impact of the double-crisis on Spanish house new supply and prices (Taltavull 2013; Taltavull, Gabrielli 2015). Those shocks would have influenced in the long term house price structure.

Although the theoretical knowledge demonstrates the existence of the diffusion or ripple effect through empirical evidence coming from UK, US and some Asian economies, there is no evidence of such influence on house prices in Spain. Therefore, it is not known how those external shocks have influenced the spatial transmission mechanism and whether or not the spatial transmission effect of housing prices hypothesis could be evidenced to exist this country.

This paper focuses on Spain and explores the existence of ripple effect in housing prices among one area receiving large flows of foreign homeowners (the tourist market), with the inland and the capital (non-turistic, local demand) in the Vega Baja, a county in the south of Alicante. The capital, Orihuela, is the administrative center of a well-known tourist area but both are physically separated around 25 kilometers. Such separation allows to observe the effect on housing prices of different demand drivers (in an administrative city and a tourist/second home international area ${ }^{1}$ ) and converts the Vega Baja in a good laboratory to bet-

\footnotetext{
${ }^{1}$ A detailed description of the Vega Baja county is in the Supplementary Appendix 1.
}

ter observe the existence of diffusion and ripple effect on house prices. On our best knowledge, this paper is the first testing the ripple effect in Spanish housing markets and using spatial autoregressive models to estimate ripple effect.

This paper also contributes to the literature by three ways. Firstly, it does not uses VAR framework analysis to estimate ripple effect as the popular method while it bases the estimation in micro data of house prices applying panel data methodology. Secondly, the detailed microdata allows to estimate ripple effect based on quality controlled house prices, so as the paper uses prices corrected by quality through a hedonic model using several number of house's attributes. This is a novelty in the literature of ripple effect. Thirdly, the model controls by space correlation and space error in order to distinguish between the unobserved correlation due to short distance proximity (called contiguous effect, same neighbourhood features) and price correlation in the long distance (no-contiguous effect), that is, it clearly identifies how diffusion effect in house prices behave by proximity. Avoiding the three aspects could generate several biases in estimation (selection and aggregation bias) invalidating the model results.

The article is organized as follows. Section 2, reviews the literature about ripple effect. Section 3 , defines the database used. Section 4, explains the modelization strategy. Section 5 , shows the results for continuous diffusion effect analysis, section 6 shows results for ripple effect and some results discussion. Section 7 , concludes.

\section{HOUSE PRICES AND RIPPLE EFFECT}

The "ripple effect" is the phenomenon where a perturbance in house price in a given market is spread out to the rest of the territory over time. In particular, ripple effect on house prices is shown as a movement (rise or fall) in house prices which affect in the same direction to other region's prices. The condition for this spatial diffusion to be recognized as ripple effect is that it is produced in a permanent way, so that the relative house prices between two places show a constant relationship in the long term.

The causes to explain the ripple effect have been related to housing demand models and household behaviour. Meen (1999) sustains that the ripple is produced due to structural differences between regions which exhibits spatial dependence with effects on housing demand and/or other house prices 
fundaments (for instance, investors could use spatial arbitrage to acquire properties in neighbour regions at lower prices). He suggests four explanations for the ripple effect: migration, equity transfer, spatial arbitrage and spatial patterns in the determinants of house prices which makes each region to respond differently to external shocks (Meen 1999). Moreover he demonstrates that the ripple effect could exist irrespective of regional structural differences and growth patterns and it is caused by adjustments within regions. The structural differences among regions tend to be stable in the long-run and reflected in a long-run constant ratio between residential prices (Holmes, Grimes 2008). Cook (2003) states that the ripple effect hypothesis implies a long-run convergence of regional UK house prices. Muellbauer and Murphy (1994) suggest equity transfer leads ripple effects when residents in a high value location purchase houses in lower-value locations.

The existence of ripple effect is, however, controversial from the theoretical perspective as the basic economic principle suggests that house prices should not move together due to house prices dependence on demand and supply conditions in each local housing markets, and they may differ across regions due to different demographic and economic environments (Lean, Smyth 2013; Canarella et al. 2012; Ashworth, Parker 1997).

Multiple evidence supporting the proposition that house price shocks in one area is likely to spread to other areas (price diffusion/ripple effect) are large in the literature (MacDonald, Taylor 1993; Alexander, Barrow 1994; Ashworth, Parker 1997; Pollakowski, Ray 1997; Tu 2000; Stevenson 2004; Cook 2005). Ripple effect has been broadly evidenced in UK as well as in other countries like Australia, US or Taiwan. It is very well known the case of UK evidenced in Meen (1999) and Cook (2003), among others, where house price changes rose first in the South-East during an upswing and then spread out to the rest of the UK over time. A number of other studies show empirical evidence on the existence of ripple effect in several countries (MacDonald, Taylor 1993; Gupta, Miller 2012; Lee, Chien 2011; Cameron et al. 2005; Canarella et al. 2012; Liu et al. 2015; Pollakowski, Ray 1997; Tu 2000; Stevenson 2004; Cook 2005; Alexander, Barrow 1994; Cook 2005) while others cannot, showing some uncertainty or limited results when testing for ripple in house prices (Ashworth, Parker 1997; Kuethe, Pede 2011; MacDonald, Taylor 1993). Research results seem to confirm that while house prices diverge in the short run, they reach a long term equilibrium gradually, that is, they move in all regions causing joint movements in the long term and supporting the hypothesis of ripple effect (Cook 2003). Ripple effect implies a long-run constancy in the ratio of house prices in different regions to the national (UK) aggregate (Meen 1999).

One implication of the ripple effect is the existence of a long-run constancy in the ratio of house prices in a given region to the national figure ${ }^{2}$. The idea of constancy in the price ratio has been assimilated to convergence and this is why the convergence-stationary analysis is commonly used to test ripple effect through estimating the ratio's stationary properties between each regional price (time series) and national house prices. Seminal papers of Meen (1999), Cook (2003) and Holmes and Grimes (2008) follow this conceptual method and many others follow them. Stationarity is explored using time series and cointegration analysis or ECV model to test for stationarity and convergence in the error correction parameter.

The use of unit root and co-integration analysis allows to explore the long-run relationship between regional house price series and permits to highlight how convergence among price series occurs (whether or not a cointegration relationship exists as the linear combination of house prices is stationary) suggesting the ripple effect. Such methodology is also used in MacDonald and Taylor (1993), Alexander and Barrow (1994) and Ashworth and Parker (1997). See Holmes and Grimes (2008) for a deep review of the literature. For instance, Alexander and Barrow (1994) uses Engle-Granger cointegration test and the vector autoregression Granger causality test to explore the relationships of regional housing markets in the South, the North and Midlands of England. Pollakowski and Ray (1997) using VAR methodology, examine the interrelationship among housing price dynamics in different US census division and metropolitan areas. They find that housing price shocks in one area would Granger-caused shocks in the same area and in contiguous areas finding limited evidence of a spatial arbitrage (diffusioneffect) across metropolitan regions in the US.

Cook and Thomas (2003) use time-varying parameter estimation, tests of Granger causality, cross correlation matrices and non-parametric methods to examine house price leadership between South East and other regions in UK. Cook

$\overline{2}$ The ratio between regional prices to the aggregate one is the referenced analysis made in UK while in other countries, the ratio tested related relative house prices in regions. 
(2003, 2005), proposes an asymmetric unit root test approach to analyse regional house price ratios to identify the convergence processes in UK house prices among regions; he also observes how asymmetric adjustment reverts to the mean faster when house prices in the South of England decrease relative to other regions. Ho et al. (2008) use Granger causality tests to identify the existence of ripple effect at spatial level across different housing submarkets classified by quality within Hong Kong for the period 1987 to 2004.

Holmes and Grimes (2008) investigate the long run convergence of regional house prices in the UK using the first principal component of house price differentials between regional and national data. They find that ratios in all regions converge towards a constant vector as the first principal component is stationary, suggesting that all UK regional house prices are driven by a single common stochastic trend, that is price changes due to a shocks ripple out across the economy. Luo et al. (2007), uses cointegracion test and Error Correction Model (VEC) tests to examine the diffusion pattern of house prices in mega-cities of Australia while Shi et al. (2009) approached ripple effects of house price movements in New Zealand using the Granger causality test, finding two diffusion paths. Lean and Smyth (2013) use cointegration, Granger causality and panel LM unit root test with structural breaks to find evidence of convergence on prices and to investigate whether the existence of unit roots could imply ripple effect on house prices between regions. Wilhelmsson (2008) analyses ripple effect and the main determinant from the demand side (aggregate data) using and ECM model among Swedish regional house prices in the long term, finding larger adjustment in periods with upturn economy and shorter in downturn.

More sophisticated VAR methods are also used. Kuethe and Pede, (2011) use quarterly state level data from 1988 to 2007 incorporating locational spill-overs through a spatial econometric adaptation of vector autoregression (SpVAR), finding that spill-overs may Granger-cause housing price movements in neighbour locations, being an evidence of how macroeconomic events ripple among regions. Lee and Chien (2011) investigate the stationary properties of Taiwan's regional house prices and analyze the diffusion effect using SURADF test in a panel non-stationary data, identifying convergence but finding limited evidence of ripple effect showed by a mix pattern of stationary ratios among pairs of regions. Liu et al. (2015) uses dynamic VAR and impulse response function to identify house price diffusion patterns among Australian state capital cities finding statistically significant lagged parameters in the VAR as capturing the house price diffusion.

Gupta and Miller (2012) includes also Bayesian, spatial and causality version of VEC models to explore real house prices relationships in the three US' MSAs, and find causality between prices in Las Vegas and Phoenix. They find evidence that migration, faster economic growth and home equity cause the diffusion effect. Holmes et al. (2011), use probabilistic test statistic based on the percentage of unit root rejections among all US state Metropolitan Areas house price differentials and including a house affordability ratio. They indicate that speed of adjustment towards long-run equilibrium is inversely related to distance.

Tsai (2014) uses static and cobweb dynamic models on panel-based unit root tests and find constancy in the relative price and trading volume ratios evidencing equilibrium in the long term between regional and national UK housing markets. These results suggest that the correction to the equilibrium is achieved first in transactions volume rather than in prices, especially after the GFC shock ${ }^{3}$.

Canarella et al. (2012), using VAR analysis tests for structural stability and linear adjustment in housing prices and finds partial evidence of ripple effect, with significance in some metropolitan areas in US but not in others. Cameron et al. (2005) estimate an annual econometric model of regional house prices in Britain over the period 1972 to 2003, incorporating spatial lags and errors and spatial coefficient heterogeneity to be used to test the transmission (ripple effect) from London house prices to house prices elsewhere.

The studies above use time series of aggregate data at national or regional/local level to approach spatial correlation as symptom of ripple effect. This implies that house heterogeneity is not observed when testing for spatial price transmission. Few literature has examined regional house prices using micro data and there is a lack on research

\footnotetext{
3 That is, the equilibrium from regional to national occurs at transaction and price levels. The frequency of convergence in transaction volume is greater than that of the overall house prices (implying a gap between buying and selling prices) and transaction volume primarily reflects the adjustment or correcting information. The paper states that the 2008 global financial crisis caused by the bankruptcy of Lehman Brothers in the United States resulted in house price convergence correction or adjustment behaviour, although the transaction volume showed divergence.
} 
using data disaggregate and with detailed features, for instance, according to the vintage, age or other features, of the housing stock (Cook 2005). Only few papers account for quality indices. Berg (2000) uses constant quality index to estimate ripple effect standardizing the reported prices with the assessed house value used for tax purposes although it uses VAR methodology demonstrating that Stockholm area to be ripple out to the other areas caused by a number of macroeconomic variables, where rate of unemployment shows strong effect on house prices and consumption. The need to account for a price index quality controlled could be a different focus to estimate the existence of convergence on house prices and ripple.

The spatial dimension (point on the map) is the centre of analysis for a limited number of studies in the literature having used micro-data with geo-spatial information to identify ripple effects, despite that it is broadly recognized that spatial dimension allows to identify with precision the diffusion effects of house prices through the point to point spatial autocorrelation measures (Holly et al. 2010).

Some studies assimilates the spatial autocorrelation to diffusion effect. They consider that the ripple effect on prices is due to non-observable changes in housing demand factors which are shown as a spatial effect, so as through calculating spatial correlation is the way to approach ripple effect or the potential permanent impact due to spatial diffusion. A seminal paper is Ashworth and Parker (1997) which test for ripple effect in an analysis of the UK regional structure of house prices including lagged spatial dependence finding some doubt on the existence of ripple effects. Bhattacharjee and Jensen-Butler (2006) estimate a spatial weights matrices based on monthly3 -digits postcode data averages for UK regions to build consistent spatial weight matrices and explore the diffusion effect of housing demand. Ma and Liu (2013) incorporate spatial methods by using spatial vector autoregression (SpVAR) model, in the Australian capital cities to capture Ripple effects between house price movements through both the temporal and spatial effects (spatial lags). Cooper et al. (2013) conduct an exploratory spatio-temporal analysis of UK housing markets for $2000-2006$, based on to a $8850 * 8850$ cross correlation matrix representing price linkage between different areas to simulate house price developments for the period 2004-2010 on a range of assumptions about income growth, population growth, house-building.
As a summary, the spatial house prices influences could be broken down into two main components. One is the pure spatial interaction coming from proximity between neighbour houses that is reflected in the autoregressive spatial parameters and captures what could be a "close-spatial pattern" in house prices. Another influence is seen as the result of social and economic factors affecting housing prices which permanently modifies the relative house prices after the spatial diffusion impacts, and could have non-continuous effect at spatial level as it is the reflection of changes in demand forces. As the latter could be persistent in the long run it is itself an evidence of ripple effect.

This paper explores the two types of spatial diffusion in Alicante, Spain. Thanks to a detailed micro-database, the analysis made here is capable to distinguish between the diffusion effect of house prices based on different distances (estimating spatial autocorrelation distance based), and the ripple among prices in three different areas, regarding house prices quality-controlled through a hedonic definition. As literature demonstrates, spatial dependence and heteroskedasticity controls in hedonic models improve the house price indices when conventional hedonic methodology is used (Anselin, Lozano-García 2008).

As our best knowledge, this is one of the first papers analysing ripple based on micro-price observations base on quality-controlled housing prices and it is the first analysing the Spanish market from the ripple effect theorem perspective.

\section{THE DATA DESCRIPTION}

This study uses micro data for la Vega Baja extracted from a large database previously tested and used in Taltavull and McGreal (2009), McGreal and Taltavull $(2012,2013)$. The original DB is a microdata panel collected information from selling prices to the whole Spain from 1995 to 2012 for valuation purposes. Only from 2007, the information is geo-coded allowing to this study to use data for 2007-2012. The extracted database was cleaned and account for 22.387 usable observations containing $29^{4}$ usable variables each individual observation relative to the socio-economic characteristics of the town, neighbourhood, building and house observed, including technical details, plus asking price, year, and geo-code (total, 33 variables). The database is very rich and allows

\footnotetext{
${ }^{4}$ Seven variables were eliminated due to the lack or very few variability.
} 


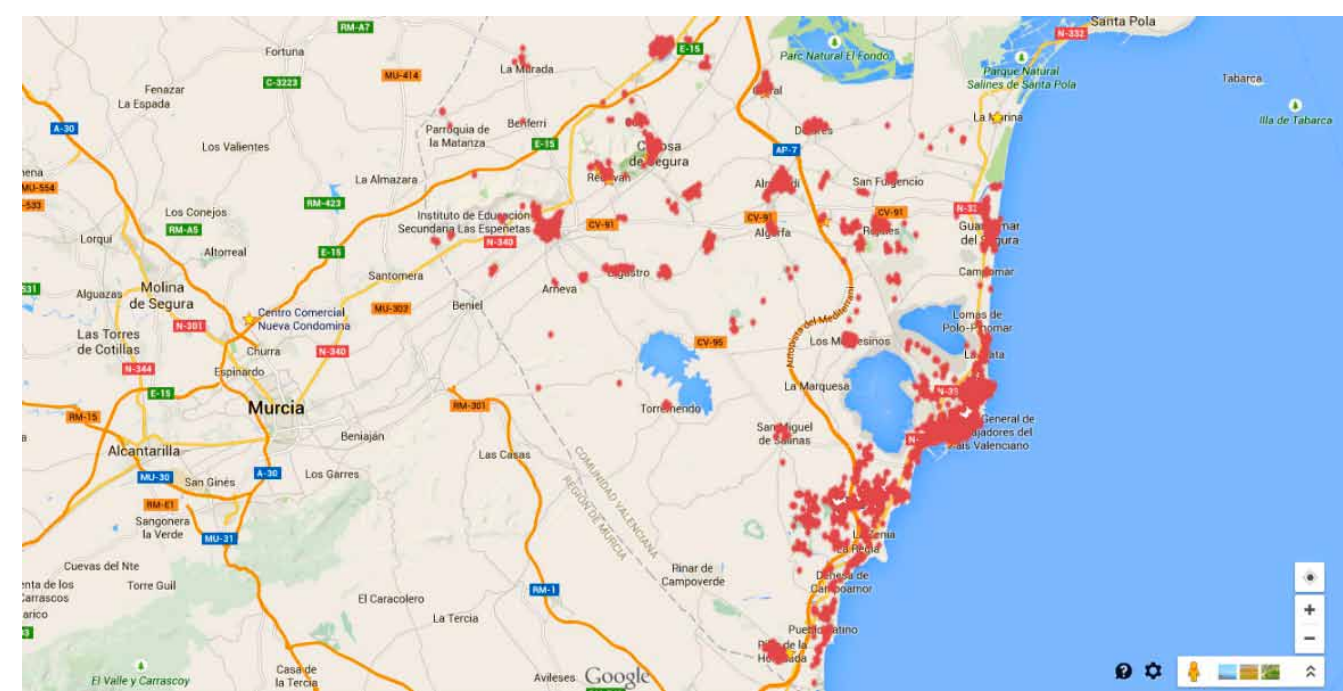

Fig. 1. Database spatial distribution in Vega Baja County (Red dots represent the houses observed) (Source: Google and author's work)

this study to control by quality in housing (asking) prices to approach the two phenomena described above as spatial diffusion and ripple effect ${ }^{5}$.To a spatial perspective, the distribution of observed data and how different housing market is located along the coast is shown in Table 1 and Figure 1.

Table 1. Evidence of local spatial autorregression in Vega Baja, Alicante at local level

\begin{tabular}{llll}
\hline \multicolumn{3}{l}{ Contiguity matrix (GAL) } & \multicolumn{2}{l}{ Distance matrix (GWT) } \\
\hline $\begin{array}{l}\text { Conti- } \\
\text { guity } \\
\text { order }\end{array}$ & $\begin{array}{l}\text { Moran's I } \\
\text { (LISA) }\end{array}$ & $\begin{array}{l}\text { Pair } \\
\text { distance } \\
\text { in km }\end{array}$ & Moran's I (LISA) \\
\hline 1 & 0.438891 & 3.18 & 0.11507 \\
2 & 0.295589 & 5 & 0.0941168 \\
5 & 0.156344 & 10 & 0.0342365 \\
10 & -0.0182231 & 15 & 0.00803265 \\
15 & -0.00158534 & 20 & -0.00214605 \\
& & \multicolumn{3}{l}{ Threshold $=3.1895 \mathrm{~km}$} \\
\hline
\end{tabular}

\section{THE RIPPLE-EFFECT MODEL AND ESTIMATION STRATEGY}

The literature above seemly highlights two different association between housing prices from the spatial perspective: the correlation related to the spatial continuity, which explains the spatial diffusion in contiguous regions, and those spatial diffusion patterns not necessarily occurring in a continuous spatial territory (but also discontinuous) being led by socio-economic characteristics of

\footnotetext{
${ }^{5}$ Basic statistics and detailed characteristics of the database are in Table III(A) and the distribution of data by town is in Table III(B) both in the Supplementary Appendix 2.
}

housing markets. It is considered that ripple effect is the result of such spatial patterns (any) if the relative house prices in two regions remains constant or converge to the equilibrium. However, the literature does not distinguishes on proximity when analyse ripple effects although it considers that each market is submitted to different demand pressures that could make their spatial patterns to follow different dynamics. This could be interpreted as that the diffusion spatial pattern could have geographical limits and that those frontiers could be over-passed as the result of socio-economic inter-relations among markets.

This paper follows this interpretation and develops the analysis in two steps. First, it estimates the local housing prices areas from the spatial perspectives defining different types of weight matrices to account for spatial autoregression based on both contiguity and the distances between each pair of properties. That is, using spatial econometrics methods to estimate Local Spatial Markets, the paper defines two types of matrices. One is contiguity matrix (gal) with $1,2,5,10$ and 15 order of contiguity. The second is $\mathrm{W}$-matrices with 3,5 , 10, 15 and 20 kilometres of distance between each pair, in order to determine the potential limits of influence of spatial correlation affecting house prices. Note that contiguity matrices capture the very close spatial correlation between each price of property and their closer first (or higher) order property prices while distance matrix defines a distance ratio and computes the house price autocorrelation between each property price and all of the other prices falling inside the circle. We assume 
that the latter could contain the detailed autocorrelation captured by the former.

Computation of the $W$ defined matrices become complex as the distance-matrix becomes larger due to that implies to capture the influence of the 22387 properties prices. The higher order/longer distance force the matrix to capture the spatial correlation pattern which increase exponentially. The far the distance is defined, the larger the influence of any shock in house prices is when the estimated autocorrelation is statistically significant. The significance of the autocorrelation patterns is approach by using Morans'I test at local level (LISA) ${ }^{6}$.

The second step looks to test evidence of noncontiguous diffusion pattern and the relative price constancy condition supported by the literature as evidence of ripple effect. As we do not use time series we cannot apply the conventional VAR-EVC models.

A Two Step Least Square method corrected spatial lag and error components (SW2SLS) is used here on our micro-data panel to estimate the constancy of the relative prices. As heterogeneous good, housing price of a particular house is related to its characteristics and house features in Vega Baja should be different due to the quality in the three observed regions (the capital, the inland and the coast). Comparing prices of houses with different characteristics should introduce bias in the estimated parameter as some changes reflecting quality shock would be interpreted as pure changes on prices, modifying the relative price value. That is why this paper first, estimates a qualitycontrolled house price and, second, approach the constancy of prices in approaching the ripple effect.

First, a homogeneous quality-controlled price value is calculated using hedonic models that is, obtaining the basic measure of prices free of quality shocks ${ }^{7}$. Following Anselin and Lozano-García (2008), spatial dependence and heteroskedasticity controls are included in hedonic models, that is, the housing price used in the ripple effect analysis should be quality constant estimated. From the hedonic theory, housing prices could be represented in a general form as equation (1):

$$
P_{i}=\alpha+\sum_{k}\left[\beta_{1 k} x_{k i}\right]+\sum_{f}\left[\beta_{2 f} x_{f i}\right]+\varepsilon_{i}
$$

\footnotetext{
${ }^{6}$ Test are computed using GEODA software.

${ }^{7}$ Which is not the same method applied by Berg (2000) and, then, not comparable.
}

where: $P_{i}-$ is the observed price for property $i$; $x$ - is a set of $(k)$ housing and building characteristics, both categorical (age, bedrooms, ...) and continuous (size..); $N$ - are another $(f)$ neighbourhood features which capture quality and amenities characteristics as well as accessibility; $\beta 1$ and $\beta 2-$ are the shadow prices of housing features and neighbourhood characteristics, to be estimated; $\alpha-$ is a parameter to be estimated capturing location fix effects; $\varepsilon$ - is the error measure.

As data includes spatial correlation patterns shown in the first step in the analysis (below), it is considered here that the dependent variable could be explained following the expression $Y=$ $\rho W y+X \beta+\lambda W \varepsilon+\mu$ with $W$ being the $\mathrm{n} \times \mathrm{n}$ spatial weights matrix, resulting in the spatial lag term $(W y)$ and $\rho$ being the spatial autoregressive parameter. The spatial error autocorrelation also means that individual errors can be defined as $E\left[\varepsilon_{\mathrm{i}} \varepsilon_{\mathrm{j}}\right]=$ $\Sigma=W \varepsilon_{\mathrm{I}}$, with $\lambda$ being the spatial error parameter and $\varepsilon$ including spillover across properties. The $\mu$ is a vector of specific location errors, with $E[\mu \mu]=\sigma^{2} \Omega$ to allow for heteroskedasticity. Then equation (1) is modified to include spatial terms in equation (2):

$$
P_{i}=\alpha+\rho W P_{i-j}+\sum_{k}\left[\beta^{\prime}{ }_{1 k} x_{k i}\right]+\sum_{f}\left[\beta^{\prime}{ }_{2 f} x_{f i}\right]+
$$

$\lambda W \varepsilon_{i}+\mu_{i}$.

where: $W-$ is the spatial weight matrix which allows estimation of the spatial association; $\beta_{1}$ and $\beta_{2}^{\prime}$ - are the robust parameters estimators for housing features and neighborhood characteristics in the spatial framework; $\rho$ - is the spatial price autoregressive parameter to be estimated, capturing the effect on prices due to the proximity of other houses; $\lambda$-is the spatial error parameter measuring the spatial association affection housing prices related to unobservable characteristics in the neighbourhood; $\mu_{\mathrm{I}}$ - is a vector of specific location error which are uncorrelated and normal distributed.

The continuous variables in the DB are measured in log terms while the categorical are in levels. Thus the results of equation (2) allow to reach the estimated quality constant prices (3):

$$
\begin{aligned}
& \hat{p}_{i}=\hat{\alpha}_{t}+\hat{p}_{t} W p_{i-j, t}+\sum_{k=1}^{k}\left[\hat{\beta}_{i k} x_{k, i}\right]+ \\
& \sum_{j=1}^{j}\left[\hat{\beta}_{2 j} x_{j, i}\right]+\hat{\lambda}_{t} W \varepsilon_{i}+\mu_{i},
\end{aligned}
$$

where all "hat" on the parameters represent that they are the estimated ones being $\hat{p}_{i}$ the quality constant prices. It gives a set of price-hat for every 
" $i$ " property estimated for each year $t$. Those prices are theoretically free of spatial short diffusion pattern as it has been counted for in (3) and the relative values among them should reflect the general influences on prices other than those coming from heterogeneity and closer spatial patterns.

Estimated prices allow to approach the constancy between relative price hat among the three regions (Orihuela, inland and coastal area) and their convergence on time, then, testing ripple effect. Constancy implies that relative price ratio will be unchanged along time, that is:

$$
\begin{aligned}
& {\left[\frac{\hat{p}_{i}}{\hat{p}_{j}}\right]_{t}=k, \text { applying logs, }} \\
& \log \left[\frac{\hat{p}_{i}}{\hat{p}_{j}}\right]_{t}=\log (k) ; \log \hat{p}_{i}-\log \hat{p}_{j}=\log (k) \\
& \log \hat{p}_{i}=\log (k)+\log \hat{p}_{j},
\end{aligned}
$$

where: $\log (\mathrm{k})=$ constant.

Estimating the equation (5) should give:

$\log \hat{p}_{i}=\gamma+\xi \log \left(\hat{p}_{j}\right) \quad ;$

and the anti-log is:

$$
\hat{p}_{i}=e^{\gamma} e^{\xi} \hat{p}_{j} ;
$$

where: $\left(e^{\gamma} e^{\xi}\right)$ is the closest estimator of $k$.

The above algebra give us the possibility to approach " $k$ " by estimating equation (6) and transforming into (7) the fitted parameters.

\section{CONTIGUOUS DIFFUSION EFFECTS ON HOUSE PRICES: SPATIAL CORRELATION ANALYSIS}

In this section, the "closest" spatial correlation is approached by calculating the spatial correlation pattern among house prices using several $\mathrm{W}$-matrices at local level (following Bhattacharjee, Jensen-Butler 2006 idea). The local analysis allow to find the existence of spatial clusters defining "areas" where the diffusion effect in house prices is developed and somehow limited by unobserved frontiers where the spatial autocorrelation ends.

As explained above, this paper defines the matrices in two ways: by contiguity and by distance in $\mathrm{km}$. The first set of matrices (gal) collect the number of continuous properties assigning those to each observation and standardizing to the unity. These matrices are symmetric and each observation is $w_{i j}^{s}=w_{i j} / \Sigma_{j} w_{i j}$. The different orders estimated here (order 1, 2, 5, 10 and 15) mean that the contiguity measures accounts for the properties located further at every order. The order determines the matrix component and how it influences to the calculation of the spatial lagged autocorrelation for each observed price. That is, the matrix order will determine the correlation between each property's housing prices with the far-lagged property located at the order chosen. For instance, with the order 10 , each correlation is the estimated between the house price property and the house price property located at the $10^{\text {th }}$ level of contiguity. It is expected that the correlation will reduce as the order increase which is consistent with the theoretical principles of distance decay functions or rent-distance gradient.

The second type of matrices are built using distance between properties in $\mathrm{km}$. Five matrices have been defined at $3 \mathrm{~km}$ (threshold distance is $3.1 \mathrm{~km}), 5,10,15$ and $20 \mathrm{~km}$. The logic expected results are similar than before.

The Moran's I is reported for each univariate test of house price applied, with a sharp reduction in the spatial auto-regressive pattern for house prices as the order/distance increases (Table 4). Results suggest a spatial autoregressive pattern in the whole region with a Morans' I test reaching 0.438 (at order 1 of contiguity, that is, the close distance) which support the hypothesis of diffusion effect in house prices at closer properties. Spatial pattern remains showing diminishing spatial autocorrelation in house prices at order 2 and 5 (Moran's $\mathrm{I}=0.29$ and 0.15 respectively). The spatial effect is converging to zero since the matrix with order five is applied and Moran's I become close to zero in higher orders which suggest that spatial autorregresion is no significant explaining prices and that prices are random distributed at those higher orders of contiguity. Same results with distance matrices are reached. The results with 3.1 kilometres of distance (threshold distance) for spatial auto-regressive calculation give Morans' I test $=0.11$ which suggest a very small spatial auto-regressive distribution when such distance is considered between every pair of property prices and house prices are randomly distributed in the territory (test close to zero ${ }^{8}$ ) when larger distances than $3.1 \mathrm{~km}$ are taking into account, suggesting none spatial pattern exists between them at such distances.

\footnotetext{
8 The value of Moran's I for contiguity order 10 and 15 are -0.0182 and -0.00158 , negative and close to zero. Similar results are for distance $15 \mathrm{~km}$ (Moran's I = 0.0080 ) and 20 (Moran's I $=-0.0021$ ). Those test values indicate that the distribution of the house prices are random at that distance as the Moran's I tests fall close to zero.
} 
Supporting those results at local level, the LISA cluster tests closely agree (using the two types of weighting matrices) and identifying the existence of two cluster at local level where spatial diffusion effects exists with clear directions. One is the south/north coasts, with the very first coastal line and the capital (which concentrate High-High spatial correlations and Low-High correlations) being an area where prices are large and growing, that is, where there is a positive spatial correlation among properties by which any increase on house prices in the neighbour property make the current property price to rise. The second is the High-Low and Low-Low category sharing the same region which is concentrated in the central area of the coast (no first line), and the inland. Those suggest that this area spread influences falling housing prices along the territory (Fig. 2). The frontiers seem to be well defined.

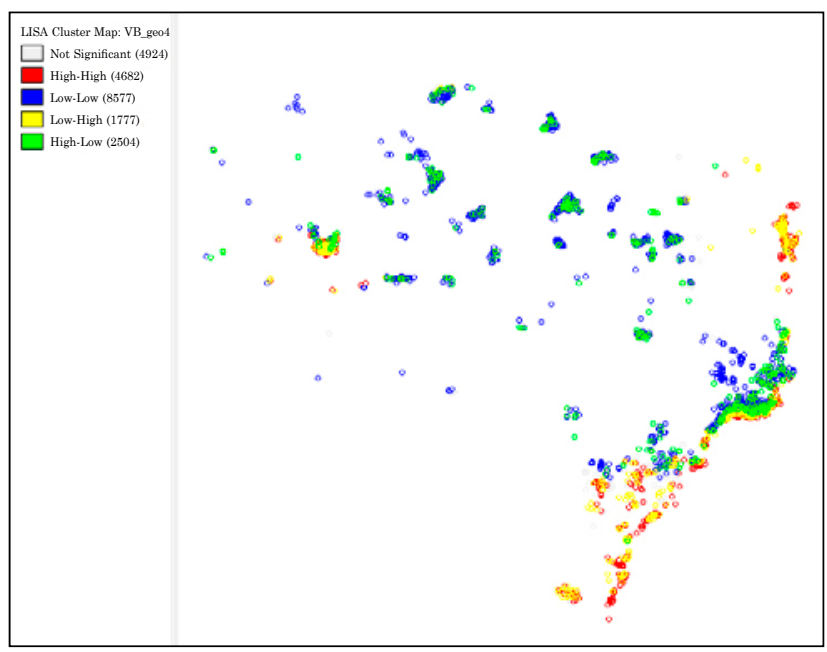

Fig. 2. LISA spatial clusters of house prices in the Vega Baja, Alicante. Weight matrix of contiguity, order 2

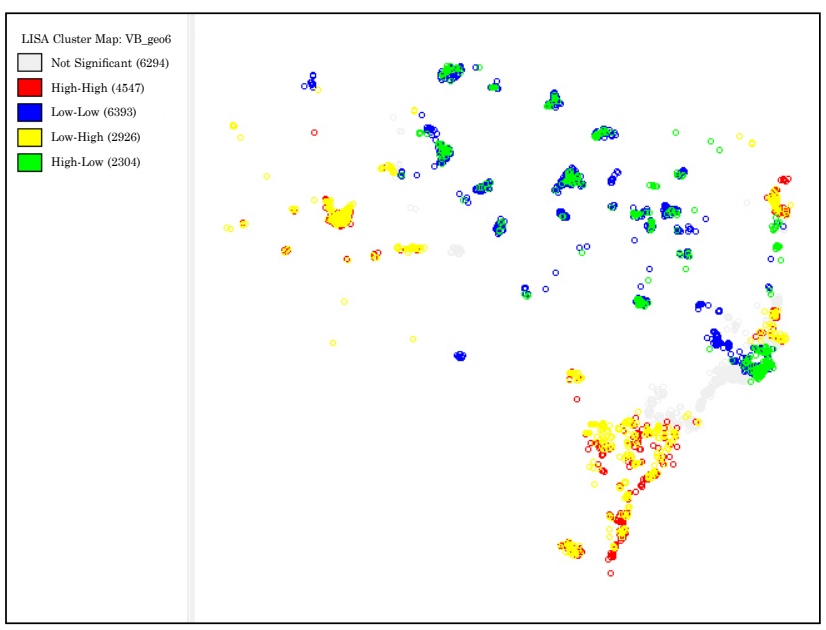

Fig. 3. LISA spatial clusters of house prices in the Vega Baja, Alicante.Weight matrix $10 \mathrm{~km}$ arc-distance
From ten kilometres onwards, LISA test shows a picture with two isolate local areas with no spatial diffusion in prices among them but intense cluster influence in the same direction inside each one, the limits and also identifies those areas in between where observations are randomly distributed with no spatial influences (Fig. 3).

In consequence, as conclusion of the estimation of spatial autoregressive test, some empirical evidence has been found about how spatial patterns affect house prices but in the short distance (which is in some way consistent with the limited evidence found in Pollakowski and Ray (1997) results) and how it diminishes as the distance becomes longer what support other empirical evidence (Holmes et al. 2011). This is compatible with the existence of clusters where the spatial effects do not disappear with the distance and their influence maintains the same direction.

\section{NO-CONTIGUOUS DIFFUSION EFFECTS: THE RIPPLE EFFECT TEST}

The second step in this paper tests ripple effect through estimating the equations 3 and 6 and calculating " $k$ ". The model does not investigate the reasons to explain potential house price diffusion or house price ripple as it focuses the analysis on quality controlled prices. This investigation gives evidence about the existence of diffusion among areas but not in terms of the basic demand perspective as no demand model is defined. Here, the diffusion effect of house prices between distant markets and its permanent effect is examined and evidenced.

Hedonic models are estimated separately by year and by main region in order to allow parameters to vary along both perspectives (area and time). The previous analysis shows evidence of spatial autocorrelation in data at cluster level. A pre-estimation test was run using Lagrange Multiplier test and Moran's I test supporting the previous evidence of spatial autocorrelation in data. Then, equation (3) is estimated using Spatially Weighted Two Stage Least Squares (SW2SLS) including spatial lag and errors in the model ${ }^{9}$. The estimated parameter is used to calculate fitted prices (p_hat).

Results show robust estimation of house prices controlled by quality, both in all years and for the

\footnotetext{
9 The full results for hedonic definition of prices from equation (3) are presented in Table IV in Supplementary Appendix 3.
} 
three spatial areas, with high explanatory capacity $\left(\operatorname{Adj} R^{2}>0.8\right)$. The three regions show consistent hedonic explanatory structure, with larger relevance of the neighbourhood quality in Orihuela and the coastal area, and more relevance of population dynamism and the use density to explain house prices in the inland region. The spatial lag parameters are significant in all equations and consistent results are at region level as well as in the case of spatial error parameter. Those agrees with the literature which identify the significance of spatial lag parameters as evidence of ripple effect, both in prices (rho parameter for spatial lagged prices) and for unobserved heterogeneity capturing spatial-other-influences (lambda parameter for spatial error, Cameron et al. 2005). Spatial error parameter is not significant in two years (2009 and 2012) for Orihuela, and in one (2012 and 2011) for the coastal area and the inland region suggesting that for those periods, the influence from unobserved variables at spatial level have not effect on housing prices.
The last step seeks to find the second evidence of ripple effect through fitting the model (7), that is, estimating the parameters which allow approach the ratio to capture the constant relationship among the prices. Constancy and convergence to the equilibrium should be an evidence of the existing ripple effect between the coast and Orihuela capital, in one hand, the inland to Orihuela capital, on the other hand.

Table 2 shows the estimated parameter and the goodness of fit of time hedonic equation. The model has been fitted between two price series, taking Orihuela prices as reference. A third model is also estimated calculating the conditional parameters of prices in the three spatial dimensions relative to the prices in Orihuela. Those parameters serve to calculate the "k" values as explained above. The estimated parameter values are consistent across the years.

The "k" values are reported in Table 3 and also reports the values of the parameters' exponents. Note that the joint model contains the conditional

Table 2. Relative price models estimation. Parameters value and explanatory capacity

\begin{tabular}{|c|c|c|c|c|c|c|}
\hline \multicolumn{7}{|c|}{$\log p_{i}=\gamma+\xi\left(\log p_{j}\right)$. Dependent variable $\log \left(p_{\text {orihuela }}\right)$} \\
\hline & 2007 & 2008 & 2009 & 2010 & 2011 & 2012 \\
\hline \multicolumn{7}{|c|}{$\log \mathrm{p}_{\text {orihuela }}=\gamma_{\mathrm{c}}+\xi_{\mathrm{c}}\left(\log \mathrm{p}_{\text {coast }}\right)$} \\
\hline$\gamma_{\mathrm{c}}$ & 2.415 & 3.162 & 3.198 & 5.037 & 2.032 & 2.291 \\
\hline$\xi_{\mathrm{c}}$ & -0.207 & -0.273 & -0.278 & -0.436 & -0.179 & -0.201 \\
\hline Adj $R^{2}$ & 0.101 & 0.1407 & 0.166 & 0.321 & 0.111 & 0.124 \\
\hline \multicolumn{7}{|c|}{$\log \mathrm{p}_{\text {orihuela }}=\gamma_{\text {in }}+\xi_{\text {in }}\left(\log \mathrm{p}_{\text {inland }}\right)$} \\
\hline$\gamma_{\text {in }}$ & 2.508 & 2.907 & 2.459 & 2.562 & 1.386 & 1.564 \\
\hline$\xi_{\text {in }}$ & -0.217 & -0.254 & -0.217 & -0.227 & -0.123 & -0.139 \\
\hline Adj $R^{2}$ & 0.110 & 0.115 & 0.088 & 0.056 & 0.047 & 0.052 \\
\hline \multicolumn{7}{|c|}{$\begin{array}{l}\text { Conditional coast and inland joint model } \\
\log \mathrm{p}_{\text {orihuela }}=\gamma_{(\mathrm{c}+\mathrm{int})}+\xi_{\text {int } / \mathrm{c}}\left(\log \mathrm{p}_{\text {inland }}\right)+\xi_{\text {c/int }}\left(\log \mathrm{p}_{\text {coast }}\right)\end{array}$} \\
\hline$\gamma_{(\mathrm{c}+\mathrm{int})}$ & 10.277 & 9.875 & 9.657 & 10.316 & 9.334 & 9.947 \\
\hline$\xi_{c / i n t}$ & -0.880 & -0.852 & -0.841 & -0.893 & -0.823 & -0.873 \\
\hline$\xi_{\text {int } / \mathrm{c}}$ & -0.891 & -0.863 & -0.854 & -0.913 & -0.831 & -0.886 \\
\hline $\operatorname{Adj} R^{2}$ & 0.882 & 0.829 & 0.846 & 0.885 & 0.829 & 0.877 \\
\hline
\end{tabular}

Table 3. Relative price model constancy estimation " $k$ " value

\begin{tabular}{|c|c|c|c|c|c|c|c|}
\hline & 2007 & 2008 & 2009 & 2010 & 2011 & 2012 & Mean \\
\hline \multicolumn{8}{|l|}{ 'k' values } \\
\hline Coastal area $\left[\mathrm{e}^{\gamma c *} \mathrm{e}^{\xi c}\right]$ & 0.9185 & 0.5791 & 0.5612 & 0.1355 & 1.1366 & 0.9759 & 0.717 \\
\hline Inland $\left[\mathrm{e}^{\gamma \text { int } *} \mathrm{e}^{\xi \operatorname{\xi int}}\right]$ & 0.8636 & 0.674 & 0.8799 & 0.8267 & 1.734 & 1.5245 & 1.083 \\
\hline 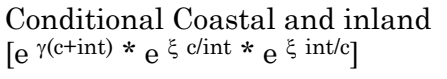 & $1.4 \mathrm{E}-08$ & $4.9 \mathrm{E}-08$ & $8.6 \mathrm{E}-08$ & 8.9E-09 & $2.2 \mathrm{E}-07$ & $2.8 \mathrm{E}-08$ & $6,7 \mathrm{E}-08$ \\
\hline \multicolumn{8}{|c|}{ Exponent of price parameter coefficients } \\
\hline Coastal area $\left[\mathrm{e}^{\xi \mathrm{c}}\right]$ & -0.499 & -0.862 & -0.890 & -2.197 & -0.364 & -0.461 & -0.871 \\
\hline 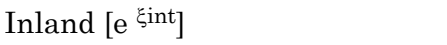 & -0.545 & -0.739 & -0.535 & -0.581 & -0.171 & -0.218 & -0.464 \\
\hline \multicolumn{8}{|l|}{ Model with conditional parameters } \\
\hline Coastal area $\left[\mathrm{e}^{\xi \mathrm{c} / \mathrm{int}}\right]$ & -9.044 & -8.411 & -8.122 & -9.215 & -7.680 & -8.688 & -8.526 \\
\hline Inland $\left[\mathrm{e}^{\xi \text { int/c }}\right]$ & -9.159 & -8.524 & -8.251 & -9.414 & -7.757 & -8.817 & -8.653 \\
\hline
\end{tabular}


parameters of prices between cost/inland to Orihuela which capture the multiple effect among prices in those areas.

Figure 4 represents the two " $k$ " values-series for coastal/Orihuela and Inland/Orihuela, both by year and the period mean. As it can be seen, there is a dissimilar evolution of both relative ratios during the analysed period. The first (coast/Orihuela) ratio returns to the equilibrium at the end of the period after to diverge since 2007, reducing from 0.9 to 0.6 , and in 2010 , with large changes making the ratio become highly volatile to return to the equilibrium in 2012. Those " $k$ " evolve around a mean value of 0,71 and reverts to the mean during the period ${ }^{10}$.

In the case of second ratio (inland/Orihuela), the " $k$ " is shown as a constant until 2010 when starts diverging until the end of period with no apparent convergence. Both periods match with the double-v crisis experience in Spain with a first shock, the GFC crisis starting in 2007, and the "austerity crisis" starting in 2010-11. The latter did strongly negatively impact on Spanish economy and especially in the households demand. The first period seems to suggest equilibrium in house prices between both regions until 2010 while the second shows a distortion on the price relations where the " $k$ " parameter strongly differs from the mean (1.08).

The model with conditional parameters gives an estimator of a combined " $k$ " with a mean of $6,7^{*} \mathrm{e}^{(-8)}$, showing the same shocks effect on house relative prices explained above (increasing volatility since 2010), but clearly converges to the equilibrium (Fig. 5) at the end of the period. Convergence to the equilibrium is also achieved by the estimated parameters values and, as an illustration, is represented in Figure 7.

The results obtained give empirical evidence of convergence relationships among housing prices between areas under study which shows different socio-economic characteristics although located at close distance. The analysed period shows the effect of shocks on relative house prices which are consistent with the 2 waves of crisis affecting Spanish economy. The change in "k" value during the first years report a reduction in house prices

10 The sample period, 2007 to 2012 , is too short to confirm without doubt that mean " $k$ " is a good benchmark of long run equilibrium. However, the empirical exercise gives evidence that it occurs during the analysed period. Further analysis with longer database should be develop to support the evidence in this paper. We acknowledge to an anonymous referee to focus in this point.

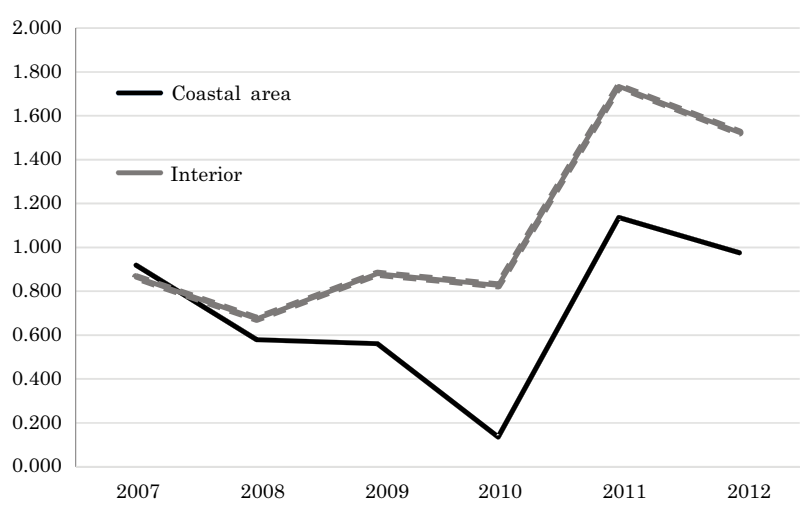

Fig. 4. Constant price relationship and convergence

$\left[\right.$ Coastal area $\left.=e^{\gamma c *} e^{\xi c}\right],\left[\right.$ Interior $\left.=e^{\gamma i n t} * e^{\xi \text { int }}\right]$

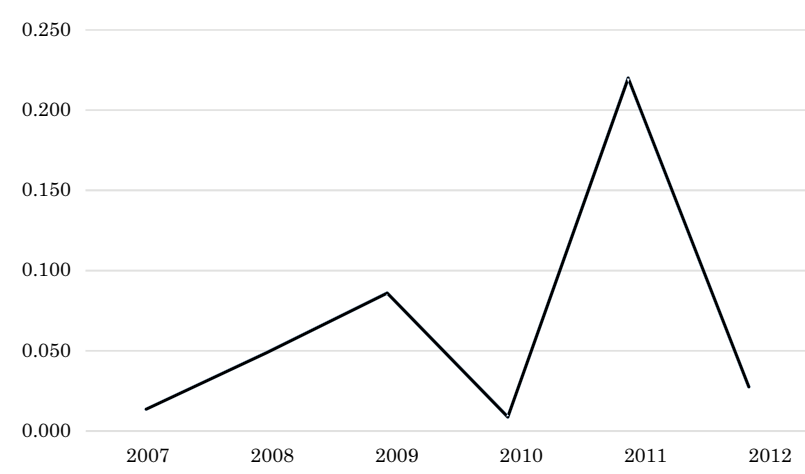

Fig. 5. Constant relationship and convergence. 'k' value for the conditional model's parameter

$$
\left[e^{\gamma(c+i n t) *} e^{\xi c / i n t *} e^{\xi i n t / c}\right]
$$

in the costs rather than in the capital. This suggest that the impact of GFC shock at worldwide level ( $1^{\text {st }}$ shock) would have reduced income (or purchase capacity) of foreign demander before the Spanish ones, lowering the foreign house demand and diminishing house prices in the coast where the demand is dominated by foreign (European) income level and flow of population, and modifying the relative to Orihuela house prices, where house market is reflecting the local socio-demographic characteristics.

The second shock (the one coming from the application of austerity measures in the Spanish Economy) had domestic effects, that is, it affected the income level to Spanish households influencing house prices dominated by domestic demand to lower. As the fall was sharp, it is consistent with how the relative " $k$ " ratio jumps up and return to the equilibrium (average " $\mathrm{k}$ ") quickly. This is consistent with results in Cook $(2003,2005)$.

Although the period of time is short to observe the full equilibrium, the described evolution seems to suggest the existence of ripple effect between the coast (dominated by foreign demand) and the 


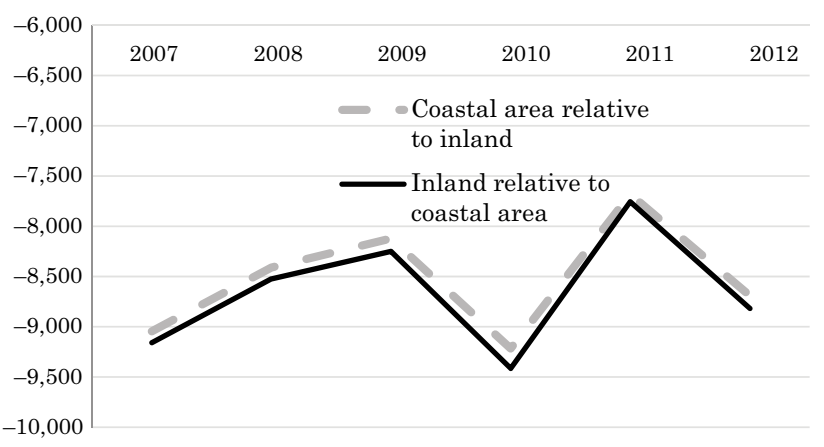

Fig. 6. Conditional estimated parameters $\xi_{\text {c/int }}$ and $\xi_{\text {int } / c}$

capital, suggesting that the former ripple the prices in Orihuela.

Dissimilar results appear in the relationship between the inland and the capital (Fig. 1). The inland is a mix area where most demand (population) is local but where there is an increasing (much less than in the coast) number of foreigners buying properties. The "k" suggests that no effect exists until 2010 and a constancy ratio between their prices and price equilibrium suggests a ripple evidence ${ }^{11}$. The " $\mathrm{k}$ " after 2010 jumps and does not return to the equilibrium suggesting that the potential impact of the austerity shock in housing prices is stronger in the capital (as before) starting a divergent period of house price distorted pattern which will take more time to converge.

In addition, taking as reference the conditional estimated parameters (Fig. 6), results clearly suggest convergence among the three territories house prices as the " $\mathrm{k}$ " is quickly returning to the equilibrium (reverting to the " $\mathrm{k}$ " mean $=-8.55$ ) at the end of the period after being affected by the 2 -wave shock. As the database ends in 2012, it is not possible to observe what happen after that year and ripple effect remains unknown only in that area.

The diffusion pattern evidenced in this paper has several policy implications. Empirical results suggest that house prices in Vega Baja receive influences from all market with long term effect (as prices ripple from the more dynamic areas). In this region, where a large part of the territory has high environmental quality and receive holidays and secondary home residence demanders, house markets for local people are affected by the pressures coming from foreign-related areas which potentially could increase prices and reduce housing supply. Those could induce to affordability problems and lack of affordable houses, affecting local households and forcing Authorities to define spe-

$\overline{11}$ This constancy is consistent with Tsai (2014) findings. cial Housing Policy measures to solve affordability problems. The demand pressure also increases the value of land promoting house-building at higher prices and contributing to rising house prices. In those circumstances, housing policy measures have to deal with the developers' reluctance to build public houses at public prices, as well as to try market price tensions to not affect public house prices. Pressures to build around the protected areas are also a relevant problem for the Authorities as the available land diminishes rapidly requiring strong policy measures to guarantee the territory sustainability. In periods of crisis, the over-supply could be a good opportunity to manage the house stock to develop housing affordability measures.

\section{CONCLUSION}

This paper analyses the house price diffusion patterns in the Vega Baja county, Alicante (Spain). This is an economic-mix region where the costal amenities strongly attract foreigner, second home buyers and temporal residents while the main region's city is an administrative centre for domestic demand. The paper explores the existence of ripple effect in housing prices among the coastal area (the foreign and tourist market), with the inland and the capital (non-tourist, local demand) which are physically far away 25 kilometers. Such separation allows to observe the effect on housing prices of different demand drivers (in an administrative city and a tourist/second home international area) using housing market in the Vega Baja as a laboratory to test the existence of diffusion and ripple effect on house prices.

The paper debates the literature showing how main studies approach the ripple effect using VARVEC methodology testing for stationarity and the existence of cointegrated relationship among house price time series, as well as looking at the VEC convergence parameter to find evidence of ripple effect. Only few literature covers this topic using quality controlled price index and/or spatial autocorrelation analysis. This paper applies both and seek for three levels of ripple effect evidence: spatial house price diffusion effect in short distances, in longer distances estimating the spatial lags, and estimating how constant the relative house price is among the key areas. The analysis is made based on quality controlled house prices calculated using hedonic methods.

Having geo-referenced variable in a database with individual observations and more than 23 thousands micro-data of house prices, the paper 
explores the ripple effect on house prices between the coastal, as holiday destination, and the inland with Orihuela capital. To control by heterogeneity and spatial autocorrelation, the model estimates housing prices controlled by quality including 33 house characteristics and spatial autocorrelation using a SAR-hedonic-based model which is estimated letting the parameters to vary across space and time. Once controlled by quality, the estimated prices are used to seek evidence of ripple effect by an algebra-definition of the ratio as an estimating their yearly value. There is a third - conditional model also estimated.

The estimated results support the existence of ripple effect by finding diffusion in house prices in the short distance, significant and consistent parameters of spatial lag and spatial error, and constancy in the house price ratio. The ratios also show the effect of two shocks during the estimated period (2007 and 2010) which are hypothesized to be the GFC and the effects of the debt crisis in Spain since 2010. Ripple effect is supported in both the coast and the capital, with a clear convergence after the two sequential shocks alter relative housing prices ratios. The inland shows a constant ratio which is not affected by the first shock but strongly affected after the second, modifying the equilibrium. Conditional parameters and relativeconditional prices " $\mathrm{k}$ " is clear in the convergence process, supporting the evidence of ripple effect.

\section{REFERENCES}

Alexander, C.; Barrow, M. 1994. Seasonality and cointegration of regional house prices in the UK, Urban Studies 31(10): 1667-1689.

https://doi.org/10.1080/00420989420081571

Anselin, L.; Lozano-García, N. 2008. Error in variables and spatial effects in hedonic house price models of ambient air quality, Empirical Economics 34(1): 5-34. https://doi.org/10.1007/s00181-007-0152-3

Ashworth, J.; Parker, S. C. 1997. Modelling regional house prices in the UK, Scottish Journal of Political Economy 44(3): 225-246.

https://doi.org/10.1111/1467-9485.00055

Berg, L. 2000. Prices on the second-hand market for Swedish family houses: correlation, causation and determinants, Working Paper, Department of Economics, Uppsala University, No. 2000:7.

Bhattacharjee, A.; Jensen-Butler, C. 2006. Estimation of the spatial weights matrix in the spatial error model, with an application to diffusion in housing demand [online]. University of St. Andrews, Dpt. of Economics WP. Available at: http://www.eea-esem.com/files/ papers/EEA-ESEM/2006/76/S13 BhattacharjeeJensen-Butler.pdf [accessed 15 March 2015]
Cameron, G.; Muelbauer, J.; Murphy, A. 2005. Booms, busts and ripples in British regional housing markets [online]. Macroeconomics, EconWPA. Available at: http://core.ac.uk/download/pdf/9314364.pdf [accessed 20 May 2015]

Canarella, G.; Miller, S. M.; Pollard, S. K. 2012. Unit roots and structural change: an application to US house-price indices, Urban Studies 49(4): 757-776. https://doi.org/10.1177/0042098011404935

Cook, S. 2003. The convergence of regional house prices in the UK, Urban Studies 40(11): 2285-2294. https://doi.org/10.1080/0042098032000123295

Cook, S. 2005. A disaggregated analysis of asymmetrical behaviour in the UK housing market, Urban Studies 43(11): 2067-2074. https://doi.org/10.1080/00420980600897735

Cook, S.; Thomas, C. 2003. An alternative approach to examining the ripple effect in UK house prices, $A p$ plied Economics Letters 10(13): 849-851. https://doi.org/10.1080/1350485032000143119

Cooper, C.; Orford, S.; Webster, C.; Jones, C. B. 2013. Exploring the ripple effect and spatial volatility in house prices in England and Wales: regressing interaction domain cross-correlations against reactive statistics, Environment and Planning B-Planning \& Desing 40(5): 763-782. https://doi.org/10.1068/b37062

Gupta, R.; Miller, S. M. 2012. "Ripple Effects" and forecasting home prices in Los Angeles, Las Vegas, and Phoenix, Annals of Regional Science 48(3): 763-782. https://doi.org/10.1007/s00168-010-0416-2

Ho, L. S.; Ma, Y.; Haurin, D. R. 2008. Domino effects within a housing market: the transmission of house price changes across quality tiers, Journal of Real Estate Finance and Economics 37(4): 299-316. https://doi.org/10.1007/s11146-007-9070-6

Holly, S.; Pesaran, M. H.; Takashi, Y. (2010) A spatiotemporal model of house prices in the USA, Journal of Econometrics 158(1): 160-173.

https://doi.org/10.1016/j.jeconom.2010.03.040

Holmes, M. J.; Grimes, A. 2008. Is there long-run convergence among regional house prices in the UK?, Urban Studies 45(8): 1531-1544. https://doi.org/10.1177/0042098008091489

Holmes, M. J.; Otero, J.; Panagiotidis, T. 2011. Investigating regional house price convergence in the United States: evidence from a pair-wise approach, Economic Modelling 28(6): 2369-2376. https://doi.org/10.1016/j.econmod.2011.06.015

Kuethe, T. H.; Pede, V. O. 2011. Regional housing price cycles: a spatio-temporal analysis using US statelevel data, Regional Studies 45(5): 563-574. https://doi.org/10.1080/00343400903497897

Lean, H. H.; Smyth, R. 2013. Regional house prices and the ripple effect in Malaysia, Urban Studies 50(5): 895-922. https://doi.org/10.1177/0042098012459582

Lee, C. C.; Chien, M. S. 2011. Empirical modelling of regional house prices and the ripple effect, Urban Studies 48(10): 2029-2047. https://doi.org/10.1177/0042098010385257

Liu, C.; Luo, Z.; Ma, L.; Picken, D. 2015. Identifying house price diffusion patterns among Australian 
state capital cities, International Journal of Strategic Property Management 12(4): 237-250.

https://doi.org/10.3846/1648-715X.2008.12.237-250

Luo, Z.; Liu, C.; Picken, D. 2007. Housing price diffusion pattern of Australia's state capital cities, International Journal of Strategic Property Management 11(4): 227-242. https://doi.org/10.1080/164871 5X.2007.9637571

Ma, L.; Liu, C. 2013. Ripple effects of house prices: considering spatial correlations in geography and demography, International Journal of Housing Markets and Analysis 6(3): 284-299. https://doi.org/10.1108/ IJHMA-05-2012-0020

MacDonald, R.; Taylor, M. P. 1993. Regional house prices in Britain: long-run relationships and short-run dynamics, Scottish Journal of Political Economy 40(1): 43-55. https://doi.org/10.1111/j.1467-9485.1993. tb00636.x

McGreal, W. S.; Taltavull de La Paz, P. 2012. An analysis of factors influencing accuracy in the valuation of residential properties in Spain, Journal of Property Research 29(1): 1-24. https://doi.org/10.1080/095999 16.2011 .589531

McGreal, W. S.; Taltavull de La Paz, P. 2013. Implicit house prices: variation over time and space in Spain, Urban Studies 50(10): 2024-2043. https://doi.org/10.1177/0042098012471978

Meen, G. 1999. Regional house prices and the ripple effect: a new interpretation, Housing Studies 14(6): 733-753. https://doi.org/10.1080/02673039982524

Muellbauer, J.; Murphy, A. 1994. Explaining regional consumption in the UK [online]. UCD Centre for Economic Research Working Paper Series WP94/29, University College Dublin. Available at: http://hdl. handle.net/10197/1770 [accessed 20 May 2015]

Pollakowski, H. O.; Ray, T. S. 1997. Housing price diffusion patterns at different aggregation levels: an examination of housing market efficiency, Journal of Housing Research 8(1): 107-124.

Shi, S.; Young, M.; Hargreaves, B. 2009. The ripple effect of local house price movements in New Zealand, Journal of Property Research 26(1): 1-24. https://doi.org/10.1080/09599910903289880

Stevenson, S. 2004. House price diffusion and inter-regional and cross-border house price dynamics, Journal of Property Research 21(4): 301-320. https://doi.org/10.1080/09599910500151228

Taltavull de La Paz, P. 2013. New housing supply and price reactions: evidence from Spanish markets, Journal of European Real Estate Research 7(1): 4-28. https://doi.org/10.1108/JERER-10-2013-0023

Taltavull de La Paz, P.; Gabrielli, L. 2015. Housing supply and price reactions: a comparison approach to Spanish and Italian markets, Housing Studies 30(7): 1036-1063.

https://doi.org/10.1080/02673037.2015.1006183

Taltavull de La Paz, P.; McGreal, S. 2009. Measuring price expectations: evidence from the Spanish housing market, Journal of European Real Estate Research 2(2): 186-209.

https://doi.org/10.1108/17539260910978481

Tsai, I-C. 2014. Ripple effect in house prices and trading volume in the UK housing market: new viewpoint and evidence, Economic Modelling 40: 68-75. https://doi.org/10.1016/j.econmod.2014.03.026

Tu, Y. 2000. Segmentation of Australian housing markets: 1989-98, Journal of Property Research 17(4): 311-327. https://doi.org/10.1080/09599910010001420

Wilhelmsson, M. 2008. Regional house prices: an application of a two-equation model to the Swedish housing market, International Journal of Housing Markets and Analysis 1(1): 33-51. https://doi.org/10.1108/17538270810861148 